Philologica Canariensia

Revista de Filología de la Universidad de las Palmas de Gran Canaria

20 (2014), eISSN: 2386-8635

DOI: en trámite

\title{
HORACIO Y EL SEXO: \\ AMOR Y SEDUCCIÓN EN LA POESÍA DE HORACIO ${ }^{1}$
}

\author{
Gabriel Laguna Mariscal \\ Universidad de Córdoba
}

\begin{abstract}
RESUMEN
En el presente trabajo se ofrece una panorámica sobre el tema amoroso en la poesía de Horacio. El amor es un tema importante, aunque no nuclear, en su poesía. Se analizan todas las modalidades de amor que contempla Horacio, según la destinataria de la relación: amor conyugal a la esposa, amor adúltero con esposas ajenas, amor no adúltero con cortesanas y sexo con prostitutas vulgares. Horacio elogia idealmente el amor matrimonial tradicional y denuesta el adulterio, pero prefiere personalmente un amor donjuanesco con múltiples parejas. Esta inclinación tiene una base literaria (pues era el sesgo dominante en el epigrama griego de época helenística), pero también responde a los gustos personales de Horacio. Se concluye que los datos extraídos de su poesía son relevantes para comprender las preferencias eróticas del Horacio hombre.

Palabras Clave: Horacio, amor, tópicos, Odas, Sátiras, Epodos, erotismo, sexo, mujer, adulterio.
\end{abstract}


ABSTRACT

In this paper, the theme of love in the poetry of Horace is surveyed. Several forms of love are distinguished: conjugal love, adulterous love with married women, love with sophisticated courtesans and plain sex with cheap prostitutes. Horace praises traditional marital love and condemns adultery, but has personally a penchant for promiscuous relationships with courtesans. This preference has a literary basis (since this was the prevailing attitude among Hellenistic epigrammatists), but it also reflects the personal attitude of Horace. The data extracted from his poetry are relevant for understanding his inner psychology. KEYwORDs: Horace, love, topoi, Odes, Satires, Epodes, eroticism, sex, woman, adultery.

\section{INTRODUCCIÓN}

No cabe duda de que el amor erótico, sin ser un tema fundamental (según discutiremos en $\int 3$ ), tiene relevancia en la poesía de Horacio. Tres amplios pasajes de las Sátiras son una denuncia del adulterio y del loco amor ${ }^{2}$. Tres composiciones de las dieciséis que constituyen el libro de Epodos son eróticas (XI, XIV y XV). Para el caso de las Odas, los comentaristas Nisbet y Hubbard (xvi) han calculado que un cuarto de las mismas son de temática amatoria. Solo en las Epistolas el tema amoroso decae considerablemente ${ }^{3}$. Este trabajo tiene como propósito analizar la visión de Horacio sobre el amor, tal como se desprende de la lectura de sus textos poéticos ${ }^{4}$, con vistas a examinar si 10 que escribe Horacio en su poesía es relevante para comprender lo que pensaba sobre el amor y el sexo.

\section{MODALIDADES DE AMOR}

\subsection{Introducción}

Horacio contempla en su poesía diferentes modalidades de relación erótica, según el estatus social y sentimental de la persona destinataria del amor. Debemos establecer una primera división entre amor conyugal (dirigido a la propia esposa o uxor) y amor no conyugal (dirigido a una mujer que no es la esposa del sujeto). A su vez, el amor no conyugal se subdivide en adúltero y no adúltero. Se entiende por amor adúltero aquella relación cuya destinataria 
es una mujer casada con otro hombre (matrona, aliena uxor ${ }^{5}$ ). Por su parte, el amor no conyugal y no adúltero tiene como objeto la relación con mujeres 'libres', en el sentido de no casadas. Estas mujeres no casadas y disponibles responden a dos tipos básicos: o bien son refinadas e independientes (meretrices); o bien se trata de prostitutas vulgares (scorta, meretriculae). De entre las cuatro destinatarias distinguidas (uxor, matrona, meretrix y scortum), dos no están en disposición de rechazar las pretensiones eróticas del sujeto: la propia esposa (uxor), por razones de débito moral y social ${ }^{6}$; y la prostituta de baja estofa (scortum), por necesidad material e inferioridad social ${ }^{7}$. En cambio, tanto la mujer casada como la cortesana refinada pueden decir que no y, en consecuencia, hay necesidad de seducción para lograr su conquista. Estas categorías se esquematizan en el siguiente cuadro ${ }^{8}$ :

\begin{tabular}{|c|c|c|c|c|c|}
\hline \multicolumn{3}{|c|}{ MODALIDAD } & \multicolumn{2}{|c|}{ DESTINATARIA } & $\begin{array}{l}\text { NECESIDAD DE } \\
\text { SEDUCCIÓN }\end{array}$ \\
\hline \multirow{4}{*}{ AMOR } & \multicolumn{2}{|c|}{ CONYUGAL } & La propia esposa & uxor & NO \\
\hline & \multirow{3}{*}{$\begin{array}{c}\text { NO } \\
\text { CONYUGAL }\end{array}$} & Adúltero & Esposa ajena & matrona & si \\
\hline & & \multirow{2}{*}{$\begin{array}{c}\text { No } \\
\text { Adúltero }\end{array}$} & Mujeres refinadas & meretrix & sí \\
\hline & & & Prostitutas vulgares & scortum & No \\
\hline
\end{tabular}

Adviértase que en el anterior esquema solo se recogen modalidades de relaciones heterosexuales (de un sujeto varón con mujeres). Sin embargo, Horacio también presenta en su obra amoríos homosexuales con mancebos (puer). Este tipo de relación será también examinada en su debido lugar (\$2.6).

\subsection{El amor conyugal}

En la Roma coetánea de Horacio y en la clase social que frecuentaba el poeta (media y alta), los matrimonios eran concertados por los padres de los novios, atendiendo a razones de conveniencia económica, social y política; los cónyuges se casaban muy jóvenes (especialmente, la novia); y el propósito básico de la unión matrimonial era perpetuar el linaje paterno mediante la procreación de hijos. Todos estos factores no propiciaban precisamente el amor romántico ni la pasión sexual en el seno del matrimonio, si 
bien promovían otros valores y actitudes, como el respeto y afecto mutuo de los cónyuges, así como la fidelidad de la mujer (Rudd, 1986, 195).

Quizá como respuesta a estos condicionamientos del matrimonio, Horacio nunca se casó; tampoco, que se sepa, tuvo hijos. Alardea, de hecho, de que es un solterón (carm. III 8, 1 caelebs). Sin embargo, en aparente paradoja, Horacio presenta varios ejemplos de relaciones conyugales ideales. Hay que admitir que el poeta no evoca estos matrimonios como reales, sino que los sitúa en un plano de irrealidad, motivada por el distanciamiento geográfico, cronológico o moral.

En el Epodo II (el famoso Beatus ille) encontramos distanciamiento geográfico. Como elemento constitutivo de la vida idílica del área rural de Italia (Sabinia, Apulia), Horacio retrata un matrimonio tradicional, que proporciona felicidad al marido, en contraste con los amoríos promiscuos del pasado, que solo le procuraban desazón? . La honesta esposa (39 pudica mulier) no es tanto objeto del amor como una pieza imprescindible esencial de la economía familiar:

quis non malarum quas amor curas habet

haec inter obliviscitur?

quodsi pudica mulier in partem iuvet

domum atque dulcis liberos,

Sabina qualis aut perusta solibus

pernicis uxor Apuli,

sacrum vetustis exstruat lignis focum

lassi sub adventum viri

claudensque textis cratibus laetum pecus

distenta siccet ubera

et horna dulci vina promens dolio

dapes inemptas adparet: (epod. II 37-48)

¿Quién no se olvida en este ambiente de las malas cuitas que conlleva el amor? Más aún si la honesta mujer colabora en lo que está en su mano con la casa y con los dulces hijos, como la esposa sabina o la del parco pullés, tostada por el sol, que apila leña seca en el sagrado hogar ante la llegada de su esposo cansado y, encerrando el rebaño en los protegidos establos, seca las repletas ubres y, extrayendo mosto fresco de la dulce tinaja, dispone manjares no comprados ${ }^{10}$. 
Documentamos un caso de distanciamiento cronológico en la estampa, situada en el pasado, presentada en la Oda III 6". La "severa madre" (39-40 severae matris) somete a una estricta disciplina a unos hijos que, dedicados ahora a la agricultura, serán en el futuro los soldados vencedores sobre Pirro, Antíoco y Aníbal:

non his iuventus orta parentibus infecit aequor sanguine Punico Pyrrumque et ingentem cecidit Antiochum Hannibalemque dirum,

sed rusticorum mascula militum

proles, Sabellis docta ligonibus versare glaebas et severae matris ad arbitrium recisos

portare fustis, sol ubi montium mutaret umbras et iuga demeret bubus fatigatis, amicum tempus agens abeunte curru. (carm. III 6, 33-44)

No una juventud nacida de padres como estos tiñó el mar de sangre púnica, y abatió a Pirro y al gran Antíoco y al fiero Aníbal, sino la viril prole de rústicos soldados, avezada en remover los terrones con azadas sabinas y a transportar ramas cortadas, a la orden de una estricta madre, cuando el sol, aportando el tiempo de descanso con la retirada de su carro, cambiaba las sombras de los montes y liberaba del yugo a los fatigados bueyes.

De la misma manera que en el Epodo II se contrastaba el cuadro conyugal con los males de los amoríos desordenados, este cuadro idílico de la familia tradicional opera en contraste con la descripción, expuesta inmediatamente antes en la $\mathrm{O} d a$, de una muchacha que, recién casada, ya incurre en adulterio (vv. 17-32).

El ideal matrimonial en Roma implicaba los siguientes requisitos: la unión debe durar toda la vida de los cónyuges, desde la primera juventud hasta la muerte $^{12}$; la relación está marcada por el afecto y respeto mutuo; tiene como 
fin la procreación de hijos (liberorum quaesundorum causa); y exige la fidelidad mutua de los esposos, pero muy especialmente de la mujer. El motivo del amor "para toda la vida" es delineado por Horacio en su Oda I 13. En esta Oda Horacio describe su amorío con Lidia (seguramente una cortesana), que le ocasiona un auténtico tormento de celos. En contraste con ese amorío desdichado, Horacio formula una alabanza (makarismós) de una unión de por vida e inmune a conflictos de pareja. En este caso, el distanciamiento entre la realidad (la relación con Lidia) y el ideal (ese matrimonio feliz) es de carácter moral ${ }^{13}$ :

felices ter et amplius

quos inrupta tenet copula nec malis

divolsus querimoniis

suprema citius solvet amor die (carm. I 13, 17-20).

¡Dichosos una y mil veces aquellos a los que abraza una unión inquebrantable y a quienes el amor, no roto por malas rencillas, no separará antes del postrero día!

\subsection{Amor no conyugal, adúltero}

Horacio recoge en diferentes pasajes, como reflejo de la realidad social, ejemplos de relaciones adúlteras con matronas romanas. Prácticamente toda la Sátira I 2 está dedicada a disuadir de tales relaciones ${ }^{14}$. Esta Sátira comienza como un denuesto filosófico de los extremos vitales y una invitación al justo medio (vv. 1-27). Un ejemplo concreto de extremismo es el gusto por tener relaciones, o bien con nobles matronas romanas, o bien con prostitutas infames:

nil medium est. sunt qui nolint tetigisse nisi illas

quarum subsuta talos tegat instita veste, contra alius nullam nisi olenti in fornice stantem. (serm. I 2, 27-30)

no hay término medio. Hay quienes sólo quieren tocar a mujeres cuyos talones los cubra un volante cosido al vestido, y otro, en cambio, no toca más que a la que se exhibe en un burdel maloliente. (traducción de Moralejo, 2008, 70-1)

A continuación, se condena el adulterio, sobre todo por razones de índole práctica: Horacio pinta los numerosos inconvenientes de mantener 
relaciones adúlteras (vv. 37-53 y 127-134). En consecuencia, considera una locura incurrir en este vicio (49 insanit).

La Sátira II 7, escrita 8 años después, incide en el mismo asunto. El esclavo Davo, aprovechando la libertad de expresión garantizada en Roma por las Fiestas Saturnales, reprocha a Horacio su gusto por el adulterio con nobles matronas: te coniunx aliena capit, meretricula Davum: / peccat uter nostrum cruce dignius? (vv. 46-47), "a ti te atrae la esposa ajena, una putilla a Davo: ¿quién peca más merecedoramente de la cruz?”. A continuación, Davo expone prolijamente los peligros e inconvenientes de las prácticas adúlteras, en línea con lo ya dicho en la Sátira I 2.

Horacio condena igualmente el adulterio en la Oda III 6, antes mencionada. En este poema se marca un contraste entre el adulterio, como práctica habitual de las casadas en la época, y los matrimonios tradicionales en Roma, totalmente ajenos al adulterio. En relación con esto, sabemos que el emperador Augusto desarrolló un programa legislativo con el objetivo de incentivar los matrimonios y la natalidad, y penar el adulterio. Se documenta la promulgación, en el año 18 a. C. (o 17) de dos Leges Iuliae. Y todo parece sugerir que, más tempranamente (hacia el 28 a. C.), Octaviano había presentado una propuesta de ley en esa línea, que fue detenida a causa de la oposición. Parece que Horacio mediante la Oda III 6 pretendió apoyar la primera iniciativa de Augusto en ese sentido, mientras que ya en el Carmen Saeculare (del 17 a. C.) o en el libro IV de las Odas (publicado en el 13 a. C.) expresa su satisfacción por que una legislación ya promulgada haya puesto coto al adulterio ${ }^{15}$ :

diva, producas subolem patrumque

prosperes decreta super iugandis

feminis prolisque novae feraci

lege marita, (Carm. saec. 17-20)

Diosa [sc. Diana], propicia la procreación y auspicia los decretos de los senadores sobre el matrimonio de las mujeres y sobre la ley matrimonial, alentadora de nueva prole.

nullis polluitur casta domus stupris, mos et lex maculosum edomuit nefas, laudantur simili prole puerperae, culpam poena premit comes. (carm. IV 5, 21-24) 
Una casta casa no es corrompida por adulterio alguno, la costumbre y la ley domeñó el sucio crimen, las madres son encomiadas por el parecido de su prole, el castigo amenaza a la culpa como un guardián.

\subsection{Amor no conyugal, no adúltero, con cortesanas}

Como se ha comentado antes, la relación legítima matrimonial no era capaz de encauzar los deseos de amor romántico. Las relaciones adulterinas, por su parte, estaban penadas legalmente (por las Leges Iuliae, antes mencionadas) y conllevaban muchos inconvenientes ${ }^{16}$. Había, pues, una necesidad social (lo que podríamos considerar una "demanda") de mujeres con las que poder entablar "liasons dangereuses". En respuesta a esa demanda, desde mediados del siglo II a. C., y concretamente desde las victorias de Roma sobre Perseo en Pidna (168 a. C.) y el saqueo de Corinto (146 a. C.), que propició la consiguiente anexión de Grecia como nueva provincia romana, se introdujeron en Roma todo tipo de refinamientos, incluyendo cortesanas de lujo (meretrices) ${ }^{17}$. Eran damas refinadas, independientes y acomodadas, hasta el punto de que tenían derecho a decir no a sus pretendientes. Los amoríos de jóvenes ciudadanos romanos con tales cortesanas eran tolerados como "pecados de juventud", en la esperanza de que los jóvenes asentarían la cabeza, se casarían y acabarían por seguir una respetable carrera política, con sujeción al mos maiorum (Cicerón, Pro Caelio 40-43) ${ }^{18}$. Estas meretrices eran frecuentemente o griegas (no es casualidad que sean griegos todos los nombres de las mujeres mencionadas por Horacio) o libertas romanas ${ }^{19}$.

Podríamos englobar a la mayoría de las amadas que menciona Horacio en sus Odas en esta categoría de meretrices refinadas. Con ellas, Horacio adopta una posición promiscua y donjuanesca. Esta es la impresión que obtenemos solo con hacer recuento de las amadas distintas que menciona en su poesía: Inaquia, Frine, Neera, Pirra, Leucónoe, Lidia, Glícera, Lálage, Clóride, Barine, Lidia, Lice, Lide, Cloe, Cínara y Filis ${ }^{20}$. Aparte de esto, Horacio confiesa en general su querencia por el amor variado, promiscuo, tanto con chicas como con chicos: in pueris aut in puellis urere (epod. XI 4), mille puellarum, puerorum mille furores (serm. II 3, 325). A pesar de esta profusión de amoríos y de la general actitud cínica de Horacio, que hace pensar que ninguna de estas cortesanas dejó una huella destacable, parece que la "buena Cínara", 
que murió joven y a la que Horacio recuerda con nostalgia en no menos de cuatro ocasiones, quizá significó algo especial.

En el ejercicio de esta actitud erótica, Horacio ha sido alineado con una de las dos corrientes de implicación emocional que se desarrollaron en el epigrama helenístico: la "desapegada”, protagonizada por Asclepíades, Posidipo, Hédilo y Calímaco, que abogaba por las relaciones promiscuas y cínicas con mancebos y con mujeres. En cambio, Horacio se aparta de la otra corriente, algo más tardía, del epigrama helenístico, que propugnaba una relación romántica con una única persona amada, con exclusividad y fidelidad; esa segunda tendencia, cuyo principal representante fue Meleagro de Gádara, sería determinante en la génesis misma de la elegía amorosa latina ${ }^{21}$.

En contadas ocasiones Horacio proclama la felicidad del amor, en la línea de algunas expresiones del epigrama helenístico ${ }^{22}$. Así, califica el amor como "dulce" o "grato"23. Tras la reconciliación con Lidia, declara su deseo de compartir toda la vida con ella, en línea con el tópico ya expuesto antes (\$ 2.2) respecto al amor conyugal: tecum niuere amem, tecum obeam libens (carm. III 9, 24). En la Oda I 22, después de afirmar el carácter inviolable y sacrosanto del enamorado ${ }^{24}$, expone su amor incondicional por Lálage, un amor que supera inconvenientes y distancias (instaura así, por cierto, un tópico literario en la tradición clásica $\left.{ }^{25}\right)$ :

pone me pigris ubi nulla campis arbor aestiva recreatur aura, quod latus mundi nebulae malusque Iuppiter urget, pone sub curru nimium propinqui solis, in terra domibus negata: dulce ridentem Lalagen amabo, dulce loquentem. (carm. I 22, 17-24)

Ponme donde, en yermos campos, ningún árbol es refrescado por la brisa estival, en el confín del mundo que las nieblas y un intempestivo Júpiter azotan; ponme bajo el carro demasiado próximo al sol, en una tierra negada a las poblaciones: amaré la dulce risa de Lálage, su dulce habla.

Pero la visión del amor predominante en Horacio es esencialmente negativa $^{26}$. El amante sufre ansiedad y desasosiego por celos. Se ve sujeto a las hu- 
millaciones de la amada, que se permite el lujo de rechazarlo de la casa, sometiéndolo a la condición de exclusus amator. El enamorado, en su obsesión, pierde el interés por su trabajo y por sus aficiones. Su reputación social se resiente, pues es motivo de murmuraciones por los mentideros de la ciudad. ${ }^{27}$ Como síntesis de esta concepción, Horacio destaca los males del amor (in amore... mala), en la estela de Terencio y de Lucrecio $^{28}$, y compara la implicación amorosa con las dos actividades reputadas como más peligrosas para la mentalidad clásica (la milicia y la navegación ${ }^{29}$ ):

in amore haec sunt mala, bellum, pax rursum: haec si quis tempestatis prope ritu mobilia et caeca fluitantia sorte laboret reddere certa sibi, nihilo plus explicet ac si insanire paret certa ratione modoque (serm. II 3, 267b-271)

En el amor ocurren esos reveses: la guerra y de nuevo la paz; y si esto, que es algo casi tan tornadizo como la tempestad y fluctúa a merced de la ciega fortuna, uno se se empeña en volverlo seguro, no ha de lograr mucho más que si pretende ser loco según un cierto modo y medida. (traducción de Moralejo, 2008, 159)

El factor principal que sustenta esta concepción general es la convicción misógina de que las mujeres, en general, son volubles, desleales e indignas del amor que les profesa el sujeto ${ }^{30}$. Así, en el epodo XV Neera le jura fidelidad al poeta, a pesar de su intención de infringir el juramento (3-4 cum tu, magnorum numen laesura deorum, / in verba iurabas mea, "cuando tú, que estabas dipuesta a ofender la divinidad de los dioses, jurabas en los términos que yo te dictaba").

En la famosa Oda a Pirra (I 5), la destinataria, hermosa y casquivana, es ya una antiguo amor de Horacio. Él ya está escarmentado de su deslealtad, y se apiada del joven amante actual de Pirra. En otra Oda (II 8), Horacio se queja de que el perjurio de Barine no le acarree un castigo divino, en aplicación de

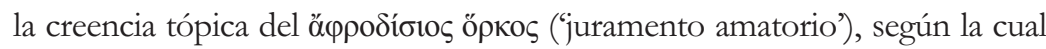
los dioses no castigan los perjurios en el ámbito de las relaciones amorosas ${ }^{31}$.

Es significativo que Horacio frecuentemente califique el amor con léxico procedente del campo semántico de la locura: insanit (serm. I 4, 27), insanire (serm. II 3, 271), furores (serm. II 3, 325), insanos amores (carm. III 21, 3). En la larga diatriba filosófica de la Sátira II 3, el amor es una de las locuras que se combate: 
aedificare casas, plostello adiungere muris, ludere par inpar, equitare in harundine longa siquem delectet barbatum, amenti verset. si puerilius his ratio esse evincet amare nec quicquam differre, utrumne in pulvere, trimus quale prius, ludas opus, an meretricis amore sollicitus plores: (serm. II 3, 247-253a)

Construir casitas, uncir ratones a un carrito, jugar a pares y nones, cabalgar sobre una larga caña... Si eso le gusta a un hombre de barba crecida, es que se ha apoderado de él la locura. Y si el razonamiento demuestra que más pueril que todo eso es enamorarse, y que no hay diferencia entre que, como hacías en otro tiempo, cuando tenías tres años, juegues en la arena, y que angustiado llores por el amor de una cortesana (traducción de Moralejo, 2008, 157-58)

Un síntoma concreto de esta locura es que el "ciego amante" (amatorem caecum) pierde la noción de la realidad, al gustar de los defectos de su amada o interpretarlos como virtudes ${ }^{32}$ :

illuc praevertamur, amatorem quod amicae turpia decipiunt caecum vitia aut etiam ipsa haec delectant, veluti Balbinum polypus Hagnae. vellem in amicitia sic erraremus et isti errori nomen virtus posuisset honestum. (serm. I 3, 38-42)

Pasemos a aquello de que al que ciega el amor se le escapan los más feos defectos que tenga su amiga, o incluso le gustan, igual que a Balbino la verruga de Hagna. Ya me gustaría que así nos equivocáramos en la amistad, y que a ese error la virtud le hubiera puesto un nombre honorable. (traducción de Moralejo, 2008, 79).

Como idea complementaria de la percepción negativa del amor, en varios pasajes Horacio expone la convicción de que la dedicación al amor romántico es disculpable en los jóvenes como "pecado de juventud", pero resulta especialmente inadecuada en hombres maduros. En la Oda II 4, al trazar un encomio de la belleza de Filis (esclava de la que Jantias está prendado), Horacio se anticipa a los posibles celos de Jantias, alegando su edad ya madura de cuarenta años, supuestamente incompatible con todo interés erótico: fuge 
suspicari / cuius octavum trepidavit aetas / claudere lustrum (vv. 22-24). En Odas II 11 el poeta reconoce que la madurez le ha acarreado falta de interés por los amoríos: arida / pellente lascivos amores / canitie (vv. 5-7). El poema inicial del libro IV de Odas está consagrado a desarrollar la tesis de que, por su edad, Horacio ha renunciado al amor, si bien Venus suscita intempestivamente una

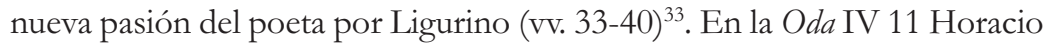
precisa que Filis será el último de sus amores (31-32 meorum / finis amorum), en razón de su edad ${ }^{34}$. En las Epistolas Horacio insiste en el motivo de que su madurez lo lleva al abandono de aficiones juveniles, como los banquetes y el amor (epist. I 14, 31-36). El paso de los años le ha quitado el gusto por el sexo y otros divertimentos: singula de nobis anni praedantur euntes: / eripuere iocos, venerem, convivia, ludum (epist. II 2, 55-56), "El paso de los años me roba todo de mí: / me arrebató las bromas, el sexo, los banquetes, el juego”.

Adviértase, por último, que gran parte de los poemas eróticos no versan sobre amoríos propios y actuales de Horacio, sino que el poeta habla sobre relaciones pasadas o ajenas ${ }^{35}$. En definitiva, Horacio pretende distanciarse de la pasión amorosa, situándola en el plano de la juventud, del pasado o de los intereses ajenos, en la idea de que dicha pasión romántica no encaja en un Horacio maduro y sensato.

\subsection{Sexo con prostitutas vulgares}

Horacio, en dos pasajes de Sátiras, ataca la locura del enamorado obsesionado y defiende la concepción epicúrea del amor. Como es sabido, Epicuro disuadía del matrimonio y del amor con implicación emocional. El filósofo y epigramatista Filodemo (110-35 a.C.) suscribió su postura. En Roma siguieron este ideario Lucilio, Lucrecio, Horacio y Propercio. Concretamente Lucrecio, como apóstol en Roma de la secta epicúrea, aconsejaba en su poema didáctico De rerum natura rehuir el amor, buscándoles defectos a las mujeres y satisfaciendo el deseo sexual mediante la uolginaga Venus, esto es, mediante relaciones esporádicas y sin establecimiento de nexos sentimentales con prostitutas ${ }^{36}$.

Horacio sigue la preferencia epicúrea del sexo mercenario ${ }^{37}$. En algún caso, Horacio califica expresamente a alguna amada como prostituta vulgar: en la Oda II 11 llama scortum a Lide. Pero es en las Sátiras donde había desarrollado más explícitamente el asunto. En la Sátira I 2 Horacio explica que las relaciones adúlteras con mujeres casadas conllevan inconvenientes en mu- 
chos aspectos (vv. 36-100), mientras que la ramera es agradable y complaciente (101-3, 121-124), de modo que constituye un medio de desahogo asequible y fácil (101-134): namque parabilem amo uenerem facilemque (v. 119). La relación con la ramera carece de los inconvenientes (legales y sociales) del adulterio:

candida rectaque sit; munda hactenus ut neque longa

nec magis alba velit quam dat natura videri.

haec ubi supposuit dextro corpus mihi laevum

Ilia et Egeria est: do nomen quodlibet illi, nec vereor ne dum futuo vir rure recurrat, ianua frangatur, latret canis, undique magno pulsa domus strepitu resonet, (serm. I 2, 123-129)

Ha de tener la tez blanca y buen talle; bien arreglada, pero sin parecer pretender más alta o más blanca de lo que se le ha dado la naturaleza. Ésta, una vez que arrime su lado izquierdo a mi lado derecho, es para mí una Ilia, una Egeria; le doy un nombre cualquiera, y no tengo miedo de que mientras jodo vuelva del campo el marido; de que rompan la puerta, de que ladre el perro, de que por doquier retumbe con gran estruendo la casa; (traducción de Moralejo, 2008, 75-76)

En la Sátira II 7 vuelve sobre el tema, esta vez en boca de Davo, esclavo de Horacio. Davo reprocha a su amo que le atraigan las esposas ajenas (46 te coniunx aliena capit), mientras que él (Davo) satisface sin problemas ni preocupaciones sus pulsiones con una prostituta vulgar (26 meretricula):

acris ubi me

natura intendit, sub clara nuda lucerna

quaecumque excepit turgentis verbera caudae, clunibus aut agitavit equum lasciva supinum, dimittit neque famosum neque sollicitum ne ditior aut formae melioris meiat eodem. (serm. II 7, 47b-52)

Cuando la ardiente naturaleza me pone tieso, quienquiera que sea la que, desnuda a la luz de un candil, recibe los azotes de mi cola turgente, o bien, lasciva, con sus nalgas me azuza como a un caballo, tendido yo boca arriba, me deja marchar sin deshonra, y sin la preocupación de si uno más rico o más guapo se corre allí mismo. (traducción de Moralejo, 2008, 184) 
2.6. Amor homosexual con efebos

Ya hemos comentado cómo Horacio se siente atraído indistintamente por muchachas y por efebos ${ }^{38}$. En el Epodo XI lamenta su sometimiento al amor de Licisco, quien alardea de vencer en atractivo a las mujeres (vv. 23-24). En las Odas se refiere a Lico, puer delicatus de Alceo (I 32, 11-12) y a Nearco, favorito de Pirro (III 20, 6). Significativamente, en la Oda IV 1, cuando Horacio cree haber renunciado al amor por razones de edad, una nueva pasión surge en él por Ligurino, que es, literalmente, el joven de sus sueños. A este mismo Ligurino dedica la $O d a$ IV 10, para criticar su desdén y augurarle por despecho un futuro desangelado.

Literariamente, Horacio se alinea en esta cuestión con la tendencia "promiscua" del epigrama helenístico, e igualmente con Catulo y con Tibulo (y en contraste con los elegíacos Propercio y Ovidio). Pero, a pesar de los críticos que niegan la realidad de este gusto por los efebos ${ }^{39}$, estas conexiones literarias no son incompatibles con la posibilidad de que Horacio se sintiera atraído por muchachos en la vida real ${ }^{40}$, como tantos otros romanos refinados de su época.

\section{3. ¿Y QUÉ NOS DICE LA POESÍA DE HORACIO SOBRE LA MEN- TALIDAD DE HORACIO?}

Una cuestión muy debatida es si hemos de detectar un trasfondo biográfico en el abigarrado panorama que emerge de este análisis. Algunos autores aceptan que lo narrado por Horacio responde a experiencias reales ${ }^{41}$. La mayoría, sin embargo, sostiene que los textos horacianos que versan sobre el amor son meras recreaciones literarias, que responden más a las fuentes literarias -sobre todo griegas- que a la realidad biográfica e histórica ${ }^{42}$. Pienso, en la línea de Commager (141-159), que se trata de un falso problema, igual que es un falso problema cuestionar la "realidad" de la elegía amorosa latina ${ }^{43}$. Esto es así, en primer lugar, porque, con independencia de que los hechos expuestos hayan ocurrido en la realidad o no, el poeta presenta esas vivencias como si fueran reales, con apariencia de realidad. Más aún, si el autor escribe, como es el caso de Horacio, dentro del género lírico (en cualquiera de sus modalidades), presenta esas vivencias impostando la voz de un sujeto que se expresa en primera persona. De hecho, no se ha destacado suficientemente que Horacio habla en 
primera persona en todos los géneros que cultivó (Sátiras, Epodos, Odas y Epístolas), con unas pocas excepciones (especialmente documentadas en los Epodos). En segundo lugar, la producción poética de un autor siempre tiene una base autobiográfica, porque la literatura es plasmación artística de unas vivencias, teniendo en cuenta la precisión de que estas "vivencias" incluyen no sólo lo estrictamente vivido, sino también lo presenciado, lo leído y lo imaginado. El poeta elabora su discurso literario tamizando y encauzando esas vivencias a través del género poético, las fuentes literarias y los recursos formales. No puedo compartir la lectura intertextual que algunos críticos pretenden imponer a toda la literatura, según la cual un texto literario es exclusivamente reflejo de otros textos. De lo que es casi siempre reflejo un texto literario es de la vida, si bien a través de la lente de la elaboración literaria.

Es cierto que el tratamiento del amor que Horacio ofrece en cada una de sus obras no es homogéneo. Hay una variación de grado y matiz, de acuerdo con las necesidades expresivas del autor y con las convenciones del género. En su primera etapa poética (Sátiras y Epodos), predomina la sátira y la invectiva contra el loco amor, con referencia a los peligros inherentes al mismo y a la degradación que conlleva. La segunda etapa (Odas), en cambio, se caracteriza por presentar con encanto la cara más ambivalente y sutil del amor: como fuerza poderosa y atractiva, aunque básicamente negativa y destructora. Por último, en el período de madurez del poeta (Epístolas), Horacio ha abandonado sus ocupaciones frívolas para consagrarse al estudio y ejercicio de la filosofía (epist. I 1, 1-11), de modo que apenas aborda la cuestión erótica. De esta evolución se desprenden tres conclusiones: 1) En ninguna de sus etapas o géneros cultivados Horacio desarrolla el amor como tema central de su poesía (a diferencia de lo que ocurre, por ejemplo, en el epigrama helenístíco, en Catulo o en los elegíacos romanos); como afirma Rudd (1986, 211): "It [sc. Love] never had the consuming intensity that it had for Catullus, and its place was never central"44. 2) El tratamiento del tema del amor en Horacio experimenta una evolución lógica, aunque siempre coherente. 3) La visión que Horacio tiene sobre el amor es siempre crítica y distanciada.

En realidad, no hay razón alguna para dudar que Horacio pensara sustancialmente lo que escribe sobre el amor en su poesía. Horacio, que se categorizó como un "cerdo del rebaño de Epicuro" (epist. I 4, 16 Epicuri de grege porcum), se mueve en la estela de la filosofía epicúrea ${ }^{45}$, que disuadía al hombre sensato de enamorarse, entendiendo el amor (así como el matrimonio y la procreación 
de hijos) como un factor desencadenante de desazón emocional. Como alternativa, el epicureísmo propugnaba las relaciones sexuales y sin implicación sentimental con rameras asequibles. Parece plausible que Horacio siguiera en su vida real las recomendaciones de la secta epicúrea, y así lo refleja en su poesía. En la vida real fue un soltero, pero muy dado a la práctica del sexo (ad res venereas intemperantior), si concedemos crédito a la picante noticia que nos transmite su biógrafo Suetonio ${ }^{46}$. En su poesía se nos muestra como un soltero, aficionado a amoríos promiscuos y variados, especialmente con refinadas cortesanas, sin desdeñar a las vulgares prostitutas ni a los efebos. Es decir, por un lado el amor y el sexo ejercen una poderosa atracción sobre Horacio; por otro lado, es muy consciente, desde su ideario filosófico, de sus efectos perniciosos. De ahí que condene críticamente el amor en Sátiras y en Epodos; nos muestre el amor en su faceta más agridulce en las Odas; y, finalmente, ignore o desprecie la dedicación al amor desde el retiro filosófico en que se ha refugiado cuando compone sus Epistolas.

En cualquier caso, Horacio no consiente que el amor invada, como tema central, su obra poética. Otros intereses y otras motivaciones merecieron ocupar la centralidad de su poesía: la vida retirada, la dedicación a la filosofía para el desarrollo de la moderación, el cultivo de la amistad, la reflexión política, la poesía misma. Como manifestación concreta de esta escala de valores, resulta significativo que, siendo Horacio el principal cultivador del tópico del carpe diem en la poesía clásica, sin embargo apenas trate el carpe diem propiamente erótico o libertino (esto es, la invitación a la amada a disfrutar del amor y del sexo, antes de que se marchite su lozanía). Por el contrario, el carpe diem horaciano incide más bien en aspectos convivales y filosóficos: disfrutar del momento presente es vivir sin preocupaciones, gozando de los pequeños placeres de la existencia (como el vino y la poesía) ${ }^{47}$.

En definitiva, no hay contradicción entre la vida y la poesía de Horacio, sino que su poesía es un espejo (todo lo adornado, estilizado y deformado que se quiera, pero espejo al fin y al cabo) de su vida y mentalidad. También en el ámbito erótico. 


\section{NOTAS}

1 Este trabajo se inscribe en el Proyecto de Investigación FFI2009-13368 del Ministerio de Ciencia e Innovación, titulado "Las Sátiras de Horacio: edición, comentario filológico y literario, y estudio de su recepción.”. El autor desea agradecer la revisión crítica de la profesora Mónica M. Martínez Sariego, así como las observaciones de los dos revisores anónimos.

2 serm. I 2, 28-134; II 3, 259-275; II 7, 46-118.

3 En alguna alusión de detalle la dedicación al amor se pinta como un vicio moral más: epist. I 6, 65-68. Encontramos también algún recuerdo puntual de los amores pasados, como las evocaciones de Cínara en epist. I 7, 27-28; I 14, 33.

4 Para el tema amatorio en las Sátiras de Horacio, véase Rudd, 1986, 197-200, 20912; en los Epodos, Alvar Ezquerra (que también incluye un interesante estudio sobre el amor en la poesía de Horacio, en general); y en las Odas, Wilkinson, 46-54; Commager ,141-159; Nisbet - Hubbard , xvi-xvii; Boyle; Lyne, 190-238; Cristóbal López, 1985, 25-26; Fedeli; Cristóbal López, 1995; Oliensis; y Ancona.

5 matronam (serm. I 2, 54), alienas /... uxores (serm. I 2, 34-35), uxoribus... alienis (serm. I 2, 57), coniunx aliena (serm. II 7, 46).

6 Ovidio, por ejemplo, incide en la cuestión de que la esposa complace por obligación y sin deseo a su esposo: odi, quae praebet, quia sit praebere necesse, / siccaque de lana cogitat usque sua; (Ars II 685-8).

7 Horacio niega a la prostituta vulgar niega el derecho a demorarse, cuando se le ordena venir: neque cunctetur cum est iussa venire (serm. I 2,122).

8 Pueden verse catálogos comparables de esquemas eróticos en Horacio en Boyle, 167 y en Fedeli. Ancona también trata sobre las categorías de mujeres en Horacio, desde una perspectiva feminista.

9 Para el contraste moral entre la ciudad y el campo, véase Harrison, 238-244. En la estela de Horacio, el motivo de la felicidad conyugal, en contraste con la infelicidad causada por los amoríos prematrimoniales, sería desarrollado por el poeta español Juan Boscán (1493-1542) en su epístola "Respuesta de Juan Boscán a don Diego Hurtado de Mendoça” (especialmente vv. 127-150).

10 Las traducciones son propias mientras no se indique lo contrario.

11 Para un estudio de esta Oda, en relación con la temática matrimonial, véase Laguna Mariscal, 1994a.

12 Compárese Catulo XLV 19-20; CIX; Propercio I 1, 31-32; II 15, 25-30; 25, 9-10; Tibulo I 6, 85-86; II 2, 17-22; [Tibulo] III 11 (IV 5), 15-16; Horacio, carm. I 13, 17 20; III 9, 24; Ovidio, Am. I 3, 5; 3, 15-18; Epist. V 157-158; Met. VIII 632-633; XIV 681-683; Trist. IV 10, 73; Marcial IV 13;Estacio, Silv. I 2, 170-171; III 5, 23-24; 5 , 106-107; C.I.L. X 3720 (véanse Williams, 1968, 370-417; 1970, 73-85; Lyne, 66-67; Giangrande, 1984, 46-47; Laguna Mariscal, 1989, 133-139; 1992, 360 y 390; 2011a, 60; Librán Moreno, 2011, 1986). 
13 Sobre esta alabanza de la relación amorosa, véase Ruiz de Elvira, 301-303 y Alcalde Pacheco - Laguna Mariscal, 136-137.

14 Fränkel, 76-86; Rudd, 1966, 30-33; 1986, 9-12 y 24-25; Brown, 100-14.

15 Para un estudio de Oda III 6 y la cuestión de la legislación matrimonial de Augusto, véase Laguna Mariscal, 1994a.

16 Estos inconvenientes son enumerados por el propio Horacio en serm. I 2, 37-53 y 127-134; II 7, 61-71.

17 Rudd, 1986, 195, Laguna Mariscal, 2011c, 110. Sobre el lujo de las cortesanas, véanse Griffin, 15-29 y García Jurado.

18 Sobre la juventud romana en el Pro Caelio de Cicerón, léase Guerrero Contreras.

19 Horacio identifica como libertas expresamente a Frine (epod. XIV 15) y a Mírtale (carm. I 33, 15).

20 Inaquia (epod. XI, XII 14-15), Frine (epod. XIV 15-16), Neera (epod. XV), Pirra (carm. I 5), Leucónoe (I 11), Lidia (I 13, I 25), Glícera (I 19; I 30; I 33; III 19, 28), Lálage (II 5, 16), Fóloe (II 5, 17; III 15, 7), Clóride (II 5, 18; III 15), Barine (II 8), Lidia (III 9), Lice (III 10; IV 13, 25), Lide (III 11, 25), Cloe (III 26, 12), Cínara (IV 1, 4; IV 13, 21-22; epist. I 7, 28; I 14, 33) y Filis (carm. IV 11).

21 Sobre estas dos corrientes en el epigrama helenístico y su influjo en la poesía latina, véanse Giangrande, 1974, 2, Alvar Ezquerra, 18-19 y Laguna Mariscal, 1998, 97 y 116.

22 Compárese A. P. V 169 (Asclepíades de Samos), imitado por Catulo LXVIII 5169 (con comentario de Laguna Mariscal, 1998, 97-100).

23 Los amores son dulces: dulcis amores (carm. I 9, 14), dulcium / ... Cupidinum (IV 14 5), dulces dominae Musa Licymniae / cantus (carm. II 12, 13-14). Los grillos que le unen con Mírtale son gratos (carm. I 33, 14-15 grata detinuit compede Myrtale / libertina), así como los que unen a Télefo y su anónima puella (carm. IV 11, 23-24 tenetque grata / compede vinctum).

24 Sobre este motivo, véase A. P. V 213 (Posidipo), XII 115 (anónimo), Tibulo I 2, 25-28, [Tibulo] III 10, 15, Propercio III 16, 11-14, Ovidio, Am. I 6, 14, con nota de Laguna Mariscal, 2011b, 103.

25 El motivo "ponme en cualquier lugar" (pone me) se desarrolla en la Canción I de Garcilaso de la Vega (vv. 1-13); en Juan Boscán, Soneto XLIII; en El Bernardo de Balbuena, libro IV (“Ponme al sol que la seca arena abrasa..."); y en Henry Howard, "Set me whereas the sun doth parch the green,..." Véanse Prieto, 67-80 y Laguna Mariscal, 2011b, 105.

26 Para la visión negativa sobre el amor en la cultura grecorromana, en general, véase Thornton; en el epigrama helenístico, Garrison, 16-32; en Horacio, Cristóbal López, 1995, 118-120, Alvar Ezquerra y Laguna Mariscal, 1998, 101-3.

27 Celos: carm. I 13 (Horacio se enfurece por celos de Lidia, que coquetea con Télefo); I 17 (Tindáride busca un refugio en la finca de Horacio para los celos violentos de Ciro); III 7 (Asterie sufre celos por Giges ausente, que coquetea con la dueña de la posada durante un viaje). Exclusus amator: epod. XI 19-22 (Horacio sufre como exclusus a las 
puertas de Licisco), serm. II 3, 259-275 (Horacio se burla de las tribulaciones del amator exclusus), carm. I 25 (Lidia somete a sus enamorados a la exclusión, aunque cada vez menos, por su progresiva pérdida de atractivo), III 10 (Horacio es despiadadamente rechazado por Lice). Pérdida de intereses: carm. I 8 (Síbaris descuida sus ejercicios atléticos por amor a Lidia); I 19, 10-12 (el amor no le deja a Horacio cultivar el género épico); III 12, 3-6 (Neóbule descuida sus labores domésticas por amor). Pérdida de la reputación: epod. XI 7-8 (Horacio, objeto de rumor por su relación con Inaquia) beu me, per V rbem-nam pudet tanti mali- / fabula quanta fuil; serm. I 2, 133; II 7, 51 y 67.

28 Terencio, Eunuchus 59-61 (59 in amore baec omnia insunt vitia), Lucrecio IV 1143-1146 (1143 in amore mala). Pueden compararse los sintagmas que describen los males de los amoríos no conyugales, que también incluyen el lexema malus: malarum... curas (epod. II 37), malis / ... querimoniis (carm. I 13, 18-19).

29 Sobre el tópico de la travesía de amor, véase Laguna Mariscal, 1999 y 2011d.

30 Así, Frine se describe como neque uno / contenta (epod. XIV 15-16). Otros casos de escandalosa deslealtad son Neera (epod. XV), Pirra (carm. I 5), Helena (I 15), Barine (II 8) y la joven matrona adúltera (III 6, 25-26). Sobre el motivo del foedus amoris violatum, véase Ramírez de Verger.

31 Este motivo se remonta a Hesíodo, frag. 124, y se documenta en Publilio Siro, Sent. 38 amantis ius iurandum poenam non habet, Tibulo I 4, 23-24; I 9, 5-6; Ovidio, Amores I 8, 85-86; III 3, 11-12. Léanse Ramírez de Verger, 337-339 y Estévez Sola, 309-10.

32 Se trata del tópico de la formulación de los defectos mediante eufemismos, para convertirlos en virtudes. El motivo, que se remonta a Platón (Rep. V 474D), había sido tratado por Lucrecio (IV 1155-1170) y lo sería después por Ovidio (Ars II 657-662). Véase Wilkinson, 114 y Moreno Soldevilla, 130.

33 A Alberto Lista (1775-1845) le debemos en "A Venus" una imitación de este texto en que documentamos un proceso de transexualización: Ligurino se convierte en Filis, porque la expresión poética del eros homosexual era, para Lista, inaceptable. Véase Martínez Sariego, en prensa.

34 Como nos recuerda Williams $(1968,119)$, el paso del tiempo es un leitmotiv en el libro IV de Odas.

35 Relaciones pasadas: carm. I 5 (sobre Pirra), III 26 (diciendo adiós al amor con Cloe). Relaciones ajenas: I 8 (Lidia tortura a Síbaris), I 33 (Glícera engaña a Albio), II 4 (Jantias, enamorado de la esclava Filis), II 12 (Mecenas y Licimnia), III 7 (Asterie llora la ausencia de Giges).

36 Epicuro: frags. 525-526 Usener; Filodemo, A. P. V 126; Lucilio: frags. 866-867 Marx; Lucrecio: V 1045-1191; Horacio: serm. I 2, 27-134 y II 7, 46-74; y Propercio: I 7 y II 23. Sobre la noción epicúrea del amor, veánse Rudd, 1966, 24-25; Laguna Mariscal, 1994b, 268-69 y n. 21; 2013; y Cristóbal López, 1995, 118-12. Sobre el tema de la uolginaga Venus en Lucrecio, léase Socas.

37 Gil lo caracteriza como "putañero" (2012, 31 y n. 103).

38 epod. XI 4 y 27-28, serm. II 3, 325. Véase Griffin, 22-26 y Rudd, 1986, 219-220. 
39 Williams, 1966, 556, Nisbet - Hubbard, 15, 71 y Moralejo, 2012, 107, quien considera que los pasajes de Horacio dedicados al deseo homoerótico "no s[on] mucho más que un brindis a la tradición literaria, y especialmente a la del alejandrinismo".

40 Como recuerda Rudd, 1986, 220: "From these few references we may conjecture $[\ldots]$ that Horace had some interest in boys, and that $[\ldots]$ in his life he remained susceptible to their attractions."

41 Por ejemplo, Griffin, 15-22 y Rudd, 1986, 209.

42 Así, Williams, 1968, 557: "Horace's erotic poems are set in a world totally removed from the Augustan State"; Nisbet - Hubbard, xiv: "The "love interest" of Horace's Odes is almost entirely Hellenistic". Alvar Ezquerra (24) sostiene que los Epodos son un "experimento literario", cuyo objetivo es parodiar y criticar la temática amorosa de la elegía romana. Moralejo $(2012,107)$ considera que "seguramente sería erróneo considerar todas y cada una de sus historias de amor por mujeres o con mujeres como testimonios de experiencias personales".

43 Veyne negó la realidad de la elegía amorosa latina. Para la polémica suscitada, véase Alcalde Pacheco - Laguna Mariscal, 127.

44 En el mismo sentido se manifiesta Oliensis, 211: "By comparison with the contemporary poets whose work we know (Virgil, Tibullus, Propertius, Ovid), Horace shows relatively little interest in the life of love".

45 Sobre esta adscripción, léanse Wilkison, $43-46$ y Cristóbal López, 1995, 118-120.

46 Suetoni vita Horati 15-17: ad res venereas intemperantior traditur; nam specula toto cubiculo dicitur habuisse disposita, ut quocumque respexisset sibi imago coitus referretur, "se cuenta que era bastante apasionado en asuntos de sexo; pues se dice que había dispuesto espejos por toda su habitación, de modo que, a donde quiera que mirase, se reflejara la imagen del coito".

47 Horacio desarrolla el tópico del carpe diem en los siguientes pasajes: epod. XIII; serm. II 6, 93-97; carm. I 4; I 9; I 11; II 3, 9-16; II 11; III 8, 25-28; III 29, 17-48; IV 7; IV 12; epist. I 4, 12-14; I 11, 22-25. Léanse Cristóbal López, 1994 y Laguna Mariscal Martínez Sariego.

\section{REFERENCIAS BIBLIOGRÁFICAS}

Alcalde Pacheco, M. J. - Laguna Mariscal, G. 2002. "La elegía II 15 de Propercio: contenido, forma, recepción”, Exemplaria 6: 123-163.

Alvar Ezquerra, A. 1997. "Los Epodos eróticos de Horacio y los inicios de la elegía latina”, Estudios Clásicos 39: 7-26.

AnCona, R. 2010. “Female Figures in Horace’s Odes”, en Davis, G. (ed.). A Companion to Horace. Malden, Mass.: Wiley-Blackwell, 174-192.

Boyle, A. J. 1973. "The Edict of Venus. An Interpretative Essay on Horace's Amatory Odes”, Ramus 2: 163-188. 
Brown, P. M. 1993. Horace. Satires I. Warminster: Aris \& Phillips.

Commager, S. 1962. The Odes of Horace. A Critical Study. New Haven - London: Yale University Press.

Cristóbal López, V. 1985. Horacio. Epodos y Odas. Madrid: Alianza Editorial.

Cristóbal López, V. 1994. "Horacio y el carpe diem”, en Cortés Tovar, R. y Fernández

Corte, J. C. (eds.). Bimilenario de Horacio. Salamanca: Servicio de Publicaciones, 171-189.

Cristóbal López, V. 1995. "Sobre el amor en las Odas de Horacio”, Cuadernos de Filología

Clásica. Estudios Latinos 8: 111-127.

Estévez SolA, J. A. 2011. "Pacto de amor”, en Moreno Soldevilla, 305-10.

Fedeli, P. 1992. "Carmi d'amore di Orazio: un percoso didattico". Aufidus 18: 59-73.

FraenKel, E. 1957. Horace. Oxford: Oxford University Press.

García Jurado, F. 1993. "Las críticas misóginas a las matronas por medio de las meretrices en la comedia latina”. Cuadernos de Filología Clásica 4: 39-48.

Garrison, D. H. 1978. Mild Frensy. A Reading of the Hellenistic Love Epigram. Wiesbaden: Franz Steiner.

Giangrande, G. 1974. "Los tópicos helenísticos en la elegía latina”, Emerita 42: 1-36.

Giangrande, G. 1984. "Motivi epigrammatici ellenistici nell' elegia romana”, en Flores,

E. (ed.). Dall' epigramma ellenistico all' elegia romana, Napoli: Istituto universitario orientale, 29-58.

GIL, J. 2012. "Prólogo”, en Moralejo, 2012, 9-32.

Griffin, J. 1985. "Augustan Poetry and the Life of Luxury”, en Griffin, J. Latin Poets and Roman Life. London: Duckworth, 1-31.

Guerrero Contreras, C. 2000. "La juventud romana en el Pro Caelio de Cicerón". Estudios Clásicos 118: 27-50.

Harrison, S. 2007. “Town and country”, en Harrison, S. (ed.). The Cambridge Companion to Horace. Cambridge: Cambridge University Press, 235-247.

La Penna, A. 1951. "Note sul linguaggio erotico dell' elegia latina”. Maia 4: 187-209.

Laguna Mariscal, G. - Martínez Sariego, M. M. 2011. “Invitación al disfrute vital”, en Moreno Soldevilla, R. (ed.). Diccionario de motivos amatorios en la literatura latina (siglos III a.C.-II d. C.). Huelva: Servicio de Publicaciones de la Universidad de Huelva, 207-11.

Laguna Mariscal, G. 1989. "Dos imágenes del léxico matrimonial en el episodio de Dafne y Apolo (Ov. Met. I 452-567): sex crines y la teas de la flamma amoris". Anuario de Estudios Filológicos 12: 133-43.

Laguna Mariscal, G. 1992. Estacio. Silvas III. Madrid-Sevilla: Fundación Pastor de Estudios Clásicos - Servicio de Publicaciones de la Universidad de Sevilla.

Laguna Mariscal, G. 1994a. "La inversión horaciana de los géneros epidícticos tradicionales: el epitalamio”, en Cortés Tovar, R. y Fernández Corte, J. C. (eds.). Bimilenario de Horacio. Salamanca: Servicio de Publicaciones, 315-321.

Laguna Mariscal, G. 1994b. "Invitación al matrimonio: en torno a un pasaje estaciano (silu. I 2, 161-200)”. Emerita 62: 263-88. 
Laguna Mariscal, G. 1998. "La poesía epigramática griega en su relación con la literatura romana: el tema amoroso", en Brioso, M. y González Ponce, F. J. (eds.). Actitudes literarias en la Grecia romana. Sevilla: Pórtico, 93-121.

Laguna MarisCaL, G. 1999. "El tópico de la tormenta del amor de la poesía grecolatina a la Tradición Clásica”, en Márquez, M. A. et al. (eds.). El retrato literario. Tempestades y naufragios. Escritura y reelaboración. Huelva: Servicio de Publicaciones de la Universidad, 435-442.

Laguna Mariscal, G. 2011a. "Amor correspondido”, en Moreno Soldevilla, 60-62.

Laguna Mariscal, G. 2011b. "Contigo al fin del mundo", en Moreno Soldevilla, 103-6.

Laguna Mariscal, G. 2011c. “Cosméticos”, en Moreno Soldevilla, 109-112.

Laguna Mariscal, G. 2011d. “Travesía de amor”, en Moreno Soldevilla, 424-426.

Laguna Mariscal, G. 2013. "La seducción en las Sátiras de Horacio: acercamiento tematológico y comparatista”, en La cultura de la seducción. Literatura y cine: más allá de la adaptación. Presencias japonesas. Salamanca: SELGYC, en prensa.

Librán Moreno, M. 2011. "Fidelidad”, en Moreno Soldevilla, 186-189.

Lyne, R. O. A. M. 1980. The Latin Love Poets. From Catullus to Horace. Oxford: Clarendon Press.

Martínez Sariego, M. M. En prensa. Horacio en Alberto Lista. Sevilla: Alfar.

Moralejo, J. L. 2008. Horacio. Sátiras. Epistolas. Arte poética. Madrid: Gredos.

Moralejo, J. L. 2012. Horacio. Madrid: Gredos.

Moreno Soldevilla, R. (ed.). 2011. Diccionario de motivos amatorios en la literatura latina (siglos III a.C.-II d. C.). Huelva: Servicio de Publicaciones de la Universidad de Huelva.

Nisbet, R. G. M. - Hubbard, M. 1970. A Commentary on Horace, Odes Book I. Oxford: University Press.

OliEnsis, E. 2007. "Erotics and Gender”, en Harrison, J. (ed.). The Cambridge Companion to Horace. Cambridge: Cambridge University Press, 221-234.

Prieto, A. 1984. La poesía española del siglo XVI. I. Andáis tras mis escritos. Madrid: Cátedra.

Ramírez de Verger, A. 1987. "La elegía I 9 de Tibulo", Veleia 4: 335-346.

RudD, N. 1966. The Satires of Horace. Cambridge: Cambridge University Press.

RudD, N. 1986. Themes in Roman Satire. London: Duckworth.

Ruiz de ElvirA, A. 1999. "Colomba y la ciencia”, en Ruiz de Elvira, A. Silva de temas clásicos y humanísticos. Murcia: Universidad de Murcia, 301-6.

SocAs, F. 1985. "Venus Volgivaga o el amor tornadizo y plebeyo". Er. Revista de Filosofía 2: 7-17.

Thornton, B. S. 1997. Eros. The Myth of Ancient Greek Sexuality. Boulder (Colorado): Westview Press.

VeYnE, P. 1991. La elegía erótica romana. El amor, la poesía y el Occidente. México: F.C.E.

WiluIAms, G. W. 1968. Tradition and Originality in Roman Poetry. Oxford: Oxford University Press.

Williams, G. W. 1970. The Nature of Roman Poetry. Oxford: Oxford University Press.

Wilkinson, L. P. 1945. Horace and his Lyric Poetry. Cambridge: Cambridge University Press. 